\title{
Viabilidade de armazenamento de sementes de soja inoculadas com Sclerotinia sclerotiorum em meio com restrição hídrica
}

\author{
Grazieli Frotas dos Reis ${ }^{1,2}$, Lilian Maria Arruda Bacchi ${ }^{1}$, Walber Luiz Gavassoni ${ }^{1}$, Lucia Mayumi Hirata ${ }^{1,2}$ \& Bruno \\ Cezar Alvaro Pontim ${ }^{1}$
}

\begin{abstract}
${ }^{1}$ Universidade Federal da Grande Dourados, Faculdade de Ciências Agrárias, Rodovia Dourados-Itahum km 12,Caixa Postal 533, 79804-970, Dourados-MS. ²Discentes do Programa de Pós-Graduação em Agronomia-Produção Vegetal/UFGD

Autor para correspondência: Lilian Maria Arruda Bacchi (lilianbacchi@ufgd.edu.br)

Data de chegada: 02/08/2013. Aceito para publicação em: 20/03/2014.
\end{abstract}

$10.1590 / 0100-5405 / 1908$

\section{RESUMO}

Reis, G.F. dos; Bacchi, L.M.A.; Gavassoni, W.L.; Hirata, L.M.; Pontim, B.C.A. Viabilidade de armazenamento de sementes de soja inoculadas com Sclerotinia sclerotiorum em meio com restrição hídrica. Summa Phytopathologica, v.40, n.2, p.168-173, 2014.

O trabalho objetivou avaliar o efeito da restrição hídrica, em meio de cultura agarizado, sobre a germinação de sementes de soja inoculadas com Sclerotinia sclerotiorum nos potenciais osmóticos de $0,-0,3,-0,6$ e -0,9 $\mathrm{MPa}$ promovido pelo uso dos solutos manitol, $\mathrm{MgCl}$ e $\mathrm{NaCl}$, em diferentes tempos de exposição das sementes ao patógeno $(6,12,18,24$ e 30 horas) e a possibilidade de armazenamento das sementes inoculadas. Avaliaramse o crescimento micelial de $S$. sclerotiorum nos meios modificados osmoticamente, a germinação das sementes submetidas à inoculação e, após o armazenamento das sementes inoculadas, a emergência em solo e transmissão do patógeno. Pelos resultados obtidos a adição de manitol ao meio de cultura BDA, nos potenciais osmóticos - $0,3,-0,6$ e $-0,9 \mathrm{MPa}$, e de $\mathrm{NaCl},-0,3$ e $-0,6 \mathrm{MPa}$, não restringe o crescimento micelial de $S$. sclerotiorum; os solutos utilizados até o potencial osmótico -0,9 $\mathrm{MPa}$ não interferiram na germinação de sementes de soja. Níveis de infecção satisfatórios foram obtidos com 24 horas de incubação em meio de cultura com restrição hídrica. Tanto a viabilidade das sementes como a do patógeno são mantidas após o armazenamento das sementes inoculadas em meio com restrição hídrica.

Palavras-chave adicionais: mofo branco, transmissão, patologia de sementes

\section{ABSTRACT}

Reis, G.F. dos; Bacchi, L.M.A.; Gavassoni, W.L.; Hirata, L.M.; Pontim, B.C.A. Viability of storage of soybean seeds inoculated with Sclerotinia sclerotiorum in medium with water restriction. Summa Phytopathologica, v.40, n.2, p.168-173, 2014.

This study aimed to evaluate the effect of water restriction, in agar medium, on the germination of soybean seeds inoculated with Sclerotinia sclerotiorum at the osmotic potentials $0,-0.3,-0.6$ and $-0.9 \mathrm{MPa}$ promoted by the use of the solutes mannitol, $\mathrm{MgCl}$ and $\mathrm{NaCl}$, at different times of seed exposure to the pathogen $(6,12,18,24$ and 30 hours), as well as the possibility of storing the inoculated seeds. The mycelial growth of $S$. sclerotiorum in the osmotically modified media, the germination of seeds subjected to inoculation and, after the storage of inoculated seeds, the emergence on the soil and the pathogen transmission were evaluated. According to the obtained results, the addition of mannitol to the PDA medium, at the osmotic potentials $-0.3,-0.6$ and -0.9 $\mathrm{MPa}$, as well as $\mathrm{NaCl},-0.3$ and $-0.6 \mathrm{MPa}$, does not limit the mycelial growth of S. sclerotiorum; the solutes used until the osmotic potential -0.9 MPa did not interfere in the germination of soybean seeds. Satisfactory infection levels were obtained with 24 hours of incubation in culture medium with water restriction. The viability of both the seeds and the pathogen is maintained after the storage of seeds inoculated in medium with water restriction.

Additional keywords: white mold, transmission, seed pathology

O Brasil ocupa lugar de destaque na produção mundial de grãos, principalmente da cultura da soja. O país é o segundo maior produtor da oleaginosa e, na safra 11/12, alcançou índices de produção de 66,67 milhões de toneladas em uma área de 25 milhões de hectares, segundo dados da CONAB (4).

As doenças podem ser consideradas o principal fator limitante de produção (7). Entre os patógenos de maior destaque na cultura da soja encontra-se o fungo Sclerotinia sclerotiorum, agente causal do mofo branco. A doença vem recebendo atenção, nos últimos anos, pelo aumento de áreas contaminadas em vários estados do país, como Paraná, Mato Grosso do Sul, Goiás e Minas Gerais, com perdas da ordem de $30 \%$, podendo atingir até $100 \%$ em períodos chuvosos, caso medidas preventivas não sejam adotadas $(2,8,9,10)$.

A associação deste patógeno com a semente constitui uma das vias mais efetivas de introdução e disseminação de inóculo em novas regiões. $\mathrm{O}$ fungo pode se associar às sementes como micélio dormente em seu interior ou acompanhando as sementes, na forma de escleródios (6). Yang et al. (20) comprovaram a transmissão de S. sclerotiorum pela semente de soja internamente infectada, demonstrando que a mesma é um agente de disseminação do patógeno para novas áreas.

A implementação de padrões de tolerância em programas de certificação de sementes é uma alternativa que pode auxiliar no controle do mofo-branco, mas, para isso, são necessários testes de diagnose precisos e eficientes e o conhecimento das taxas de transmissão 
do patógeno via sementes. A quantificação dos danos reais desta associação fungo-semente vem sendo estudada em diversas pesquisas, entretanto existe a necessidade de se trabalhar com sementes inoculadas artificialmente em laboratório. Neste sentido, Peres $(14,15)$ verificou que a inoculação de sementes de soja, pelo contato destas com colônias de Sclerotinia sclerotiorum, em meio BDA por 30 horas de exposição, apresentou uma contaminação entre $35 \%$ a $100 \%$. Entretanto, este período de incubação das sementes pode desencadear o início das fases de germinação, o que o torna um tanto insatisfatório quando se pretende submeter estas sementes a outros testes, como o de germinação.

A restrição hídrica baseia-se em modificar o potencial osmótico de meios de cultura ou substratos utilizando solutos osmóticos. O uso da restrição hídrica se mostra promissor em vários trabalhos $(11,12,13,17)$, e essa técnica vem sendo testada como método de evitar a germinação de sementes em testes de sanidade sem afetar a detecção de fungos. Neste trabalho, o objetivo foi avaliar o efeito da restrição hídrica, em meio de cultura agarizado, sobre a germinação de sementes de soja inoculadas com Sclerotinia sclerotiorum em diferentes potenciais osmóticos e tempos de inoculação, buscando condições de inoculação satisfatórias e a possibilidade de armazenamento das sementes após a inoculação, quanto à manutenção da viabilidade do patógeno e da semente.

\section{MATERIAL E MÉTODOS}

Os ensaios foram conduzidos no Laboratório de Fitopatologia da Universidade Federal da Grande Dourados (UFGD), no período de novembro de 2011 a junho de 2012.

As sementes de soja utilizadas, da cultivar BRS 245, foram submetidas aos testes de germinação e sanidade para avaliação de sua qualidade, apresentando baixos índices de patógenos contaminantes e germinação em torno de $90 \%$.

Testes preliminares foram realizados a fim de ajustar os tratamentos conforme descrito abaixo:

Crescimento micelial em meio de cultura osmoticamente modificado: avaliaram-se os efeitos da restrição hídrica em relação ao crescimento micelial de Sclerotinia sclerotiorum utilizando-se meio BDA (extrato de batata - dextrose - ágar) osmoticamente modificado. Os níveis de potencial osmótico desejados foram obtidos adicionando-se manitol, $\mathrm{MgCl}$ e $\mathrm{NaCl}$ ao meio BDA nos potenciais hídricos de -0,3,0,6 e -0,9 MPa para cada soluto utilizado.

As concentrações para o preparo dos meios, em cada potencial hídrico foram obtidas por meio da fórmula proposta por Van't Hoff (18), $\Psi$ os = - RTC.

em que:

Yos = potencial osmótico (atm);

$\mathrm{R}=$ constante geral dos gases perfeitos $(0,082 \mathrm{~atm}$ mol L-1 K-1);

$\mathrm{T}=$ temperatura $(\mathrm{K})$;

$\mathrm{C}=$ concentração (mol L-1); mol L-1 x massa molar de C6H14O6 $=\mathrm{g} \mathrm{L}-1$
As quantidades dos solutos utilizados, em gramas/litro de meio BDA, para obter cada nível de potencial osmótico avaliado, estão apresentadas na Tabela1.

Utilizou-se o delineamento experimental inteiramente casualizado com 10 tratamentos e cinco repetições. Os tratamentos foram os seguintes: BDA + Man -0,3 MPa, BDA + Man -0,6 MPa, BDA + Man $-0,9 \mathrm{MPa}, \mathrm{BDA}+\mathrm{MgCl}-0,3 \mathrm{MPa}, \mathrm{BDA}+\mathrm{MgCl}-0,6 \mathrm{MPa}, \mathrm{BDA}+$ $\mathrm{MgCl}-0,9 \mathrm{MPa}, \mathrm{BDA}+\mathrm{NaCl}-0,3 \mathrm{MPa}, \mathrm{BDA}+\mathrm{NaCl}-0,6 \mathrm{MPa}, \mathrm{BDA}$ $+\mathrm{NaCl}-0,9 \mathrm{MPa}, \mathrm{BDA}$ - testemunha.

O meio BDA ajustado aos níveis de potenciais osmóticos desejados, após esterilização, foi distribuído em placas de Petri de 9 $\mathrm{cm}$ de diâmetro, utilizando $20 \mathrm{ml}$ por placa. No centro de cada placa, foi colocado um disco de meio de cultura de $0,5 \mathrm{~cm}$ com micélio de Sclerotinia sclerotiorum. As placas foram mantidas em câmara do tipo BOD em escuro contínuo à temperatura de $20 \pm 2^{\circ} \mathrm{C}$ (16). O diâmetro médio das colônias foi mensurado, em centímetros, utilizando-se régua transparente comum, medindo-se no verso de cada placa o crescimento micelial do fungo, a cada 24 horas, até que a colônia ocupasse toda placa num total de três avaliações. Para avaliação do crescimento micelial das colônias fúngicas, foram realizadas medições do crescimento radial da colônia em dois eixos ortogonais, descartando-se o disco repicado da colônia pura, sendo posteriormente calculada uma média.

Os dados foram submetidos à análise de variância com auxílio do SANEST e as médias comparadas pelo teste de Tukey.

Tempo de inoculação e germinação em rolo de papel: as sementes de soja foram incubadas pelos períodos de 6, 12, 18 e 24 horas em placas de Petri nos seguintes meios: BDA + Man -0,3 MPa, BDA + Man -0,6 $\mathrm{MPa}, \mathrm{BDA}+\mathrm{Man}-0,9 \mathrm{MPa}, \mathrm{BDA}+\mathrm{MgCl}-0,3 \mathrm{MPa}, \mathrm{BDA}+\mathrm{MgCl}$ $-0,6 \mathrm{MPa}, \mathrm{BDA}+\mathrm{MgCl}-0,9 \mathrm{MPa}, \mathrm{BDA}+\mathrm{NaCl}-0,3 \mathrm{MPa}, \mathrm{BDA}+$ $\mathrm{NaCl}-0,6 \mathrm{MPa}, \mathrm{BDA}+\mathrm{NaCl}$-0,9 MPa e BDA. Após cada período de incubação, as sementes permaneceram em temperatura ambiente por 24 horas, em seguida foram submetidas ao teste de germinação em rolo de papel, umedecidos com água destilada 2,5 vezes o peso do papel. Os rolos foram levados para um germinador regulado a $25^{\circ} \mathrm{C}$ por oito dias (1). Na avaliação, foram computadas as porcentagens de plântulas normais, anormais e sementes mortas (1). Utilizou-se o delineamento experimental inteiramente casualizado em esquema fatorial $4 \times 10$, sendo quatro tempos de incubação e dez meios, com quatro repetições de 50 sementes por tratamento. Os dados foram submetidos à análise de variância, teste de médias (Tukey) para o fator meio de cultura e regressão polinomial para o fator tempo de exposição das sementes ao meio.

Emergência em solo e transmissão semente - plântula - Para obtenção das sementes utilizadas neste ensaio, placas de Petri contendo os meios de cultura BDA e BDA + Man -0,3 MPa receberam um disco de meio de cultura de $0,3 \mathrm{~cm}$ de diâmetro com micélio de $S$. sclerotiorum. Quando a placa estava completamente tomada pelo micélio do fungo, sementes de soja foram colocadas nas placas onde permaneceram pelos tempos de 18, 24 e 30 horas. Os tratamentos constaram da

Tabela 1. Quantidade de manitol, $\mathrm{MgCl}$ e $\mathrm{NaCl}$ utilizada para ajustar o meio BDA em diferentes níveis de potencial osmótico.

\begin{tabular}{|c|c|c|c|}
\hline \multirow{2}{*}{$\begin{array}{l}\text { Potencial osmótico ajustado do meio } \\
\text { BDA (MPa) }\end{array}$} & \multicolumn{3}{|c|}{ g. $\mathrm{L}^{-1}$ de meio BDA } \\
\hline & Manitol & $\mathrm{Mg} \mathrm{Cl}$ & $\mathrm{NaCl}$ \\
\hline$-0,3$ & 22,29 & 6,85 & 4,20 \\
\hline$-0,6$ & 44,58 & 13,71 & 8,40 \\
\hline$-0,9$ & 66,87 & 20,56 & 12,60 \\
\hline
\end{tabular}


combinação meios x tempos, BDA 18, 24 e 30 horas, BDA+ Man -0,3 MPa 18, 24 e 30 horas, além da incubação das sementes pelos mesmos tempos em placas contendo apenas ágar-água. As sementes inoculadas foram submetidas ao teste aos 20 e 94 dias de armazenamento após a inoculação.

O teste de emergência foi realizado em bandejas plásticas de $47 \times 27 \times 08 \mathrm{~cm}$, contendo solo de barranco esterilizado, utilizandose quatro repetições de 50 sementes por tratamento, semeadas na profundidade aproximada de $1,5 \mathrm{~cm}$. As bandejas foram distribuídas ao acaso numa sala de crescimento vegetal, à temperatura de $22^{\circ} \mathrm{C}$ e fotoperíodo alternado de 12 horas. As avaliações foram realizadas aos cinco e sete dias após a semeadura, computando-se o número de plântulas emergidas, plântulas com sintomas e mortas e não germinadas. Entre sementes não germinadas, foi possível observar um crescimento micelial característico de S. sclerotiorum na superfície da bandeja; esses dados foram computados como sinais do patógeno e foi calculada a porcentagem de sementes não germinadas com sinais.

Aos nove dias, as plântulas assintomáticas foram retiradas, lavadas em água corrente e incubadas para verificação da possível transmissão semente- plântula de Sclerotinia sclerotiorum. Estas foram acondicionadas em gerbox, contendo três folhas de papel de germinação e incubadas em câmara tipo BOD a temperatura de $20 \pm 2^{\circ} \mathrm{C}$ em escuro contínuo por 10 a 15 dias. Calculou-se a porcentagem de transmissão semente - plântula relacionando-se o numero de plântulas incubadas e o número de plântulas que após o período de incubação apresentaram formação de escleródios.

Os dados de porcentagem de emergência aos 5 e 7 dias, porcentagem de sementes mortas e porcentagem de sementes mortas com sinais foram submetidos à análise de variância e, as médias, comparadas pelo teste de Tukey com auxílio do SANEST.

\section{RESULTADOS E DISCUSSÃO}

\section{Crescimento micelial em meio de cultura osmoticamente} modificado

O crescimento micelial de $S$. sclerotiorum se mostrou diferenciado com adição de solutos no meio de cultura, tanto em relação ao soluto como ao nível de restrição utilizado (Tabela 2). Na avaliação do crescimento micelial de $S$. sclerotiorum feita com 24 horas, observou-se que o uso do soluto $\mathrm{MgCl}$, no potencial de $-0,6$ proporcionou um maior crescimento micelial de $S$. sclerotiorum, diferindo estatisticamente da testemunha. Esse efeito, no entanto, não se manteve até 72 horas de incubação do fungo na presença deste soluto. Machado et al. (13) observaram um estímulo no crescimento micelial de Fusarium oxysporum f. sp. vasinfectum em meio BDA modificado osmoticamente com manitol até o nível de $-1,0 \mathrm{MPa}$.

Na avaliação realizada com 48 horas de incubação, detectou-se um menor diâmetro da colônia do fungo quando na presença dos solutos $\mathrm{MgCl}$, nos níveis de restrição hídrica de $-0,3$ e $0,9 \mathrm{MPa}$, e $\mathrm{NaCl}-0,9$ MPa (Tabela 2). Carvalho et al. (3) observaram que colônias de $C$. lindemuthianum apresentam um maior diâmetro médio em BDA modificado osmoticamente com manitol, superior a testemunha, até o nível de restrição de $-0,6 \mathrm{MPa}$, tendendo ao declínio em potenciais hídricos mais negativos até a restrição de -1,0 MPa, o que evidencia que algumas associações de solutos com potenciais hídricos altos podem alterar negativamente o crescimento da colônia de alguns fungos.

Com 72 horas de crescimento do fungo, o efeito de redução no crescimento micelial foi observado apenas para o meio com $\mathrm{MgCl}-0,9$ $\mathrm{MPa}$ (Tabela 2). Nesta avaliação, detectou-se um maior crescimento de S. sclerotiorum na presença de manitol, ao nível -0,9 MPa. Coutinho et al. (5) relacionaram um maior crescimento micelial de F. oxysporum f.sp. phaseoli, Macrophomina phaseolina e Rhizoctonia solani em meio de cultura ajustado osmoticamente com manitol, ao nível de - 0,7 e - $0,8 \mathrm{MPa}$, à utilização desse açúcar como fonte adicional de energia pelos fungos. Machado et al. (11) também observaram que o manitol não reduziu o crescimento micelial de Colletotrichum truncatum, Sclerotinia sclerotiorum e Phomopsis sojae em sementes de soja sob estresse hídrico variando de -0,4 a 1,0 MPa no meio de cultura BDA, apresentando efeito estimulante quando comparado ao meio sem restrição.

Os meios utilizados promoveram o desenvolvimento de $S$. sclerotiorum, entretanto, a utilização do soluto $\mathrm{MgCl}$ nas concentrações de -0,6 e -0,9 MPa dificultou a solidificação do meio, além de causar uma modificação na coloração do BDA. Por estes motivos o uso deste soluto foi descartado para avaliações posteriores.

Tabela 2. Diâmetro micelial (cm) de Sclerotinia sclerotiorum em meio de cultura BDA modificado osmoticamente por diferentes solutos, às 24,48 e 72 horas de incubação.

\begin{tabular}{cccc}
\hline & & Diâmetro & 72 horas \\
\hline TRATAMENTOS & 24 horas & 48 horas & $7,38 \mathrm{abc}$ \\
BDA+MAN-03 MPa & $0,52 \mathrm{~b}$ & $2,65 \mathrm{abc}$ & $7,34 \mathrm{abc}$ \\
BDA+MAN-06 MPa & $0,51 \mathrm{~b}$ & $2,55 \mathrm{abc}$ & $7,94 \mathrm{a}$ \\
BDA+MAN-09 MPa & $0,56 \mathrm{~b}$ & $3,01 \mathrm{a}$ & $6,87 \mathrm{c}$ \\
BDA+MgCl-03 MPa & $0,51 \mathrm{~b}$ & $2,25 \mathrm{c}$ & $7,32 \mathrm{abc}$ \\
BDA+MgCl-06 MPa & $0,70 \mathrm{a}$ & $2,82 \mathrm{ab}$ & $5,10 \mathrm{~d}$ \\
BDA+MgCl-09 MPa & $0,61 \mathrm{ab}$ & $1,19 \mathrm{~d}$ & $7,63 \mathrm{ab}$ \\
BDA+NaCl-03 MPa & $0,58 \mathrm{~b}$ & $2,74 \mathrm{abc}$ & $7,27 \mathrm{bc}$ \\
BDA+NaCl-06 MPa & $0,62 \mathrm{ab}$ & $2,58 \mathrm{abc}$ & $6,91 \mathrm{c}$ \\
BDA+NaCl-09 MPa & $0,61 \mathrm{ab}$ & $2,34 \mathrm{bc}$ & $7,31 \mathrm{bc}$ \\
\hline
\end{tabular}

Médias seguidas de mesma letra na coluna não diferem entre si pelo teste de Tukey a $5 \%$. 
Tabela 3. Valores médios de emergência em solo (\%) aos 5 e 7 dias, de sementes de soja inoculadas com Sclerotinia sclerotiorum em meio de cultura batatadextrose-ágar com (MAN) e sem (BDA)restrição hídrica por 18, 24 e 30 horas e armazenadas por 20 e 94 dias.

\begin{tabular}{|c|c|c|c|c|c|c|c|c|}
\hline & \multicolumn{4}{|c|}{ \% Emergência 5 dias } & \multicolumn{4}{|c|}{ \% Emergência 7 dias } \\
\hline & \multicolumn{8}{|c|}{20 dias de armazenamento } \\
\hline & 18 & 24 & 30 & médias & 18 & 24 & 30 & médias \\
\hline Test.* & 48,5 & 57,5 & 34,0 & $46,7 \mathrm{a}$ & $78,0 \mathrm{a} B$ & $90,0 \mathrm{a} A$ & $83,5 \mathrm{aAB}$ & 83,8 \\
\hline BDA & 22,0 & 23,0 & 14,0 & $19,7 \mathrm{~b}$ & $32,5 \mathrm{bA}$ & $31,5 \mathrm{bA}$ & $20,0 \mathrm{bA}$ & 28,0 \\
\hline MAN $-0,3$ & 24,0 & 9,0 & 19,5 & $17,5 \mathrm{~b}$ & $43,0 \mathrm{bA}$ & $26 \mathrm{~b}$ B & $30,0 \mathrm{bAB}$ & 33,0 \\
\hline médias & $31,5 \mathrm{~A}$ & $29,84 \mathrm{~A}$ & $22,5 \mathrm{~A}$ & & 51,17 & 49,17 & 44,5 & \\
\hline \multirow[t]{2}{*}{ CV\% } & 40,63 & & & & 12,00 & & & \\
\hline & \multicolumn{8}{|c|}{94 dias de armazenamento } \\
\hline Test. & 22,5 & 13,0 & 10,5 & $15,33 \mathrm{a}$ & $72,5 \mathrm{aA}$ & $79,0 \mathrm{a} A$ & $75,0 \mathrm{aA}$ & 75,5 \\
\hline BDA & 5,0 & 4,5 & 5,0 & $4,83 \mathrm{~b}$ & $35,0 \mathrm{bAB}$ & 21,0 c B & $35,5 \mathrm{bA}$ & 30,5 \\
\hline MAN $-0,3$ & 10,0 & 14,0 & 12,5 & $12,17 \mathrm{ab}$ & $43,0 \mathrm{bA}$ & $56,5 \mathrm{bA}$ & $49,5 \mathrm{bA}$ & 49,67 \\
\hline Médias & $12,5 \mathrm{~A}$ & $10,5 \mathrm{~A}$ & $9,33 \mathrm{~A}$ & & 50,17 & 52,17 & 53,33 & \\
\hline $\mathrm{CV} \%$ & 51,88 & & & & 11,07 & & & \\
\hline
\end{tabular}

Médias seguidas de mesma letra, minúscula na coluna e maiúscula na linha, não diferem entre si pelo teste de Tukey a 5\%, dentro de cada tempo de armazenamento e para cada data de avaliação.

* agar-água sem adição de restritor hídrico e sem presença de $S$. sclerotiorum

\section{Tempo de inoculação e germinação em rolo de papel}

Não foram detectados efeitos do meio de incubação e do tempo de incubação das sementes nesses meios sobre a germinação das mesmas. Quando as sementes foram deixadas em contato com os meios com restrição hídrica, por até 24 horas, posteriormente retiradas e submetidas ao teste de germinação apresentaram porcentagens de germinação próximas a da testemunha $0 \mathrm{MPa}$. $\mathrm{O}$ uso de manitol, $\mathrm{MgCl}$ e $\mathrm{NaCl}$, nos potenciais osmóticos $-0,3 \mathrm{MPa},-0,6 \mathrm{MPa}$ e $-0,9 \mathrm{MPa}$ não afetou a germinação das sementes, que ficou em torno de $95 \%$ (dados não apresentados). Santos (19) relatou que sementes de soja submetidas ao teste de germinação, em rolo de papel umedecido com diferentes solutos, apresentaram valores acima de $65 \%$ de germinação com o uso de manitol a -0,9 MPa.

Visualmente os tempos de 6 horas e 12 horas não promoveram uma boa cobertura das sementes com o inóculo, apenas uma pequena quantidade de micélio ficou aderida à superfície das sementes, o que os torna insuficientes para promover a inoculação das sementes.

Sementes incubadas no meio osmoticamente modificado pelo soluto $\mathrm{MgCl}$ nos potenciais de -0,6 MPa e -0,9 MPa apresentaram plântulas com radícula escurecida, sugerindo algum tipo de toxidez, o que poderia comprometer um teste de emergência em solo e uma posterior avaliação sanitária desta plântula.

\section{Emergência em solo}

$\mathrm{Na}$ avaliação de emergência em solo, para sementes armazenadas pelo período de 20 dias, observou-se que nas sementes inoculadas com S. sclerotiorum, os estandes aos cinco dias após a semeadura foram reduzidos, não havendo diferença estatística entre o meio com restritor manitol e apenas BDA (Tabela 3). Na avaliação aos sete dias de emergência, houve interação significativa entre os meios utilizados e o tempo de inoculação. Um maior percentual de emergência foi observado na testemunha sem inoculação. Não houve diferença estatística entre o meio manitol -0,3 MPa e BDA, para todos os períodos de inoculação das sementes. Comparando-se os períodos de inoculação, não houve diferença entre eles quando o meio utilizado, para a inoculação de $S$. sclerotiorum em sementes de soja, foi o BDA (sem restrição hídrica). No meio de cultura com restrição hídrica (MAN -0,3), menor porcentagem de emergência foi detectada em sementes inoculadas por 24 horas. As porcentagens de emergência, quando as sementes foram inoculadas com o fungo, foram entre $20 \%$ e $43 \%$, sendo que Machado et al. (11), avaliando a inoculação artificial de sementes de soja por S. sclerotiorum pelo tempo de 48 horas, observaram índices de emergência em torno de $20 \%$, em meio sem restrição hídrica. No entanto, esses autores detectaram diferença estatística entre a porcentagem de emergência para sementes inoculadas em meios com e sem restrição hídrica, o que não foi observado neste trabalho, no caso de sementes armazenadas por 20 dias após a inoculação.

Para sementes armazenadas por 94 dias, houve diferença estatística entre os meios para avaliação de emergência aos cinco dias (Tabela 3). As sementes inoculadas no meio sem restrição hídrica apresentaram a menor porcentagem de emergência, no entanto, sem diferir daquelas inoculadas no meio com adição de manitol. Já aos sete dias, os resultados obtidos evidenciaram interação entre os meios e o tempo de exposição da semente ao patógeno. Os maiores valores foram observados para testemunha sem inoculação, não havendo diferença estatística para emergência entre sementes incubadas em meio sem e com restrição hídrica, exceto para o tempo de 24 horas, onde sementes incubadas em meio sem restrição hídrica apresentaram menores índices de emergência.

Não houve diferença entre porcentagens de sementes mortas com sinais do patógeno observadas para inoculação em BDA sem e com restrição hídrica, independente do tempo de exposição ao patógeno, para sementes armazenadas pelo período de 20 dias (Tabela 4). Para o mesmo critério de avaliação, em sementes armazenadas por 94 dias houve interação significativa entre meio e tempo de exposição da semente ao patógeno, sendo que para 24 horas de exposição, observou-se maior percentual de sinais do patógeno para BDA sem restrição hídrica.

$\mathrm{O}$ fungo provocou a morte das sementes, provavelmente como consequência do maior nível de potencial de inóculo determinado por essa exposição das sementes ao patógeno, o que se evidencia pela redução na porcentagem de plântulas emergidas e no aumento da porcentagem de sementes mortas com sinais do patógeno, comparandose os tratamentos com inoculação ao tratamento testemunha (sem inoculação) (Tabelas 3 e 4 respectivamente). No entanto, para porcentagem de plântulas mortas após a emergência, detectou-se efeito da inoculação apenas para sementes, armazenadas por 20 dias, após 
a inoculação em meio sem restrição hídrica, independente do tempo de exposição da semente ao fungo, que diferiu da testemunha sem inoculação, mas foi estatisticamente igual ao resultado obtido em meio com manitol (Tabela 4).

Foi possível observar transmissão semente - plântula, nos dois períodos de armazenamento (Figura 1). Plântulas oriundas de sementes de soja, inoculadas em meio BDA e MAN por 24 e 30 horas, armazenadas por 20 dias, tiveram taxas de transmissão variando de $5 \%$ a $15 \%$. Aos 94 dias de armazenamento para o tratamento BDA, foi possível observar transmissão apenas para o tempo de 24 horas, onde o nível de transmissão foi próximo de $12 \%$. Para o meio com restrição hídrica (manitol $-0,3 \mathrm{MPa}$ ), níveis de transmissão acima de $13 \%$ e $15 \%$ foram observados para os tempos de 24 e 30 horas de incubação, respectivamente. Para as sementes que permaneceram 18 horas expostas à colônia fúngica, as plântulas emergidas não apresentaram o patógeno após 94 dias de armazenamento. Com 20 dias de armazenamento das sementes inoculadas, o patógeno só foi observado nas sementes que haviam recebido a inoculação em meio com restritor hídrico neste período de exposição.

\section{CONCLUSÃO}

Período mínimo de 24 horas de incubação de sementes de soja com Sclerotinia sclerotiorum, em meio de cultura com restrição hídrica, possibilita melhor inoculação das sementes.

É possível o armazenamento por 94 dias, de sementes de soja inoculadas com Sclerotinia sclerotiorum em meio com restrição hídrica, mantendo-se a viabilidade das sementes e do patógeno .

\section{AGRADECIMENTOS}

Ao CNPq pelo suporte financeiro e a Fundect/MS pela concessão de bolsa ao primeiro autor.

Tabela 4. Porcentagem de plântulas mortas e de sementes não germinadas com sinais de Sclerotinia sclerotiorum, oriundas de sementes de soja submetidas a inoculação artificial em meio batata-dextrose-ágar com (MAN) e sem (BDA) restrição hídrica, por 18, 24 e 30 horas, após o armazenamento por 20 e 94 dias.

\begin{tabular}{|c|c|c|c|c|c|c|c|c|}
\hline & \multicolumn{4}{|c|}{ \% Plântulas Mortas } & \multicolumn{4}{|c|}{$\%$ Sementes com Sinais } \\
\hline & \multicolumn{8}{|c|}{20 dias de armazenamento } \\
\hline & 18 & 24 & 30 & médias & 18 & 24 & 30 & médias \\
\hline Test.* & 0,0 & 0,0 & 0,0 & $0,00 \mathrm{~b}$ & 0,00 & 0,00 & 0,00 & $0,00 \mathrm{~b}$ \\
\hline BDA & 3,0 & 2,5 & 1,0 & $2,17 \mathrm{a}$ & 41,13 & 39,57 & 40,88 & $40,53 \mathrm{a}$ \\
\hline MAN $-0,3$ & 0,5 & 2,5 & 2,0 & $1,67 \mathrm{ab}$ & 45,99 & 35,83 & 25,71 & $35,84 \mathrm{a}$ \\
\hline médias & $1,17 \mathrm{~A}$ & $1,67 \mathrm{~A}$ & $1,0 \mathrm{~A}$ & & $29,04 \mathrm{~A}$ & $25,13 \mathrm{~A}$ & $22,2 \mathrm{~A}$ & \\
\hline \multirow[t]{2}{*}{$\mathrm{CV} \%$} & 137,7 & & & & 19,9 & & & \\
\hline & \multicolumn{8}{|c|}{94 dias de armazenamento } \\
\hline Test. & 0,0 & 0,0 & 0,0 & $0,0 \mathrm{a}$ & $0,00 \mathrm{bA}$ & $0,00 \quad \mathrm{bA}$ & $0,00 \mathrm{bA}$ & 0,00 \\
\hline BDA & 0,5 & 0,5 & 2,0 & $1,0 \mathrm{a}$ & $32,34 \mathrm{a} A$ & $28,13 \mathrm{a} A$ & $21,37 \mathrm{a} \mathrm{A}$ & 27,28 \\
\hline MAN $-0,3$ & 0,5 & 0,5 & 0,5 & $0,5 \mathrm{a}$ & $26,21 \mathrm{a} \mathrm{A}$ & $12,04 \mathrm{~b} \mathrm{~B}$ & $36,15 \mathrm{a} A$ & 24,80 \\
\hline Médias & $0,33 \mathrm{~A}$ & $0,33 \mathrm{~A}$ & $0,83 \mathrm{~A}$ & & 19,52 & 20,08 & 28,76 & \\
\hline $\mathrm{CV} \%$ & 212,21 & & & & 51,23 & & & \\
\hline
\end{tabular}

Médias seguidas de mesma letra minúscula na coluna e maiúscula na linha, não diferem entre si pelo teste de Tukey a $5 \%$, dentro de cada período de armazenamento.

* agar-água sem adição de restritor hídrico e sem presença de S. sclerotiorum

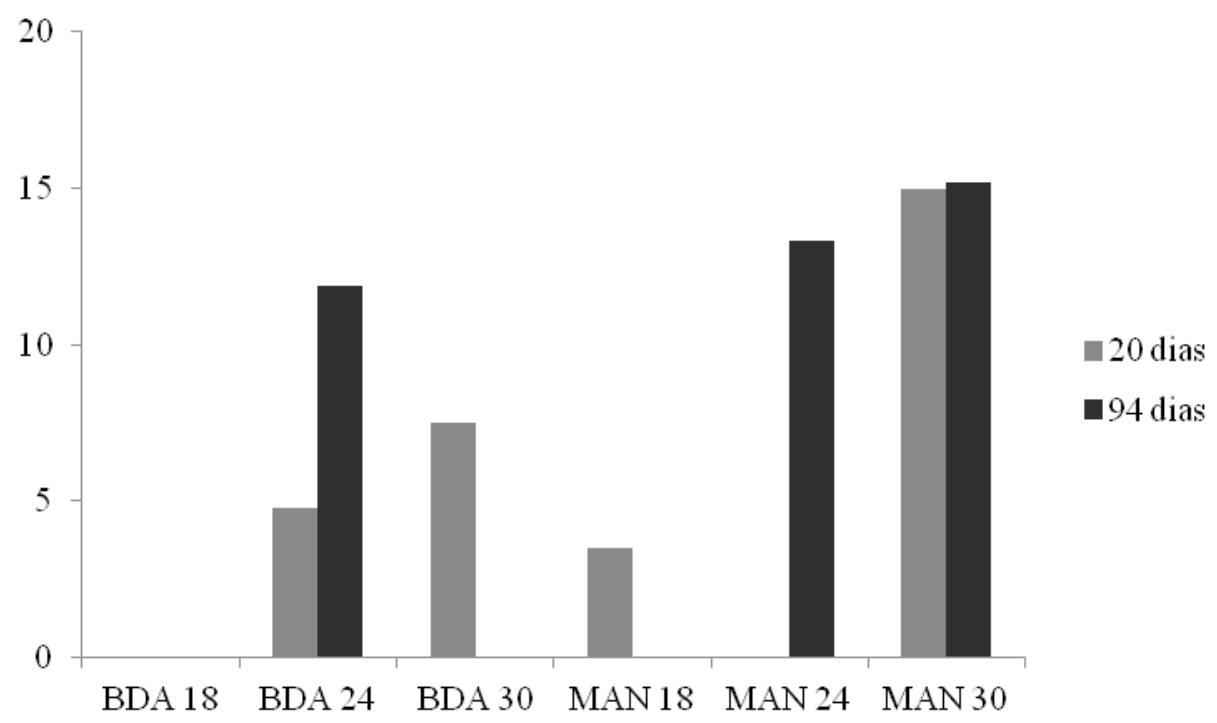

Figura 1. Porcentagem de transmissão semente - plântula de Sclerotinia sclerotiorum em sementes de soja armazenadas por 20 e 94 dias após inoculação, por 18 , 24 e 30 horas, em meio batata-dextrose-ágar (BDA) e BDA com manitol-0,3MPa (MAN). 


\section{REFERÊNCIAS BIBLIOGRÁFICAS}

1. Brasil. Ministério da Agricultura e Reforma Agrária. Regras para Análise de Sementes. Brasília, DF; 2009. 395 p.

2. Carregal, L. H.; Campos, H. D.; Silva, J. R. C. Saiba mais sobre mofo branco. 2005 Disponível em: http://www.ihara.com.br/index/ezsite. asp?ID=2065. Acesso em: 25 jul. 2012.

3. Carvalho, J. C. B.; Machado, J. C.; Vieira, G. M. Crescimento micelial de Colletotrichum lindemuthianum em relação à restrição hídrica do substrato agarizado. Ciência Agrotécnica, Lavras, v. 25, n. 4, p. 999- 1005, 2001.

4. Companhia Nacional de Abastecimento. Acompanhamento de safra brasileira: grãos, décimo levantamento, julho, 2012. Brasília; DF : Conab, 2012. 29 p. http://www.conab.gov.br/OlalaCMS/uploads/arquivos/12_07_05_08_41_20_boletim_graos___10julho_2012.pdf. Acesso em: 26 jul. 2012

5. Coutinho, W. M .; Machado, J. C.; Vieira, M. G. G. C. Uso da restrição hídrica na inibição ou retardamento da germinação de sementes de arroz e feijão submetidas ao teste de sanidade em meio ágar-água. Revista Brasileira de Sementes, Pelotas, v. 23, n. 2, p. 127-135, 2001.

6. Dhingra, O. D. Teoria da transmissão de patógeno fúngico por sementes. In: ZAMBOLIM, L. (ed.) Sementes: qualidade fitossanitária. Viçosa: UFV, 2005. p.75-112.

7. Goulart, A. C. P. Tratamento de sementes de soja com fungicidas. In: ZAMBOLIM, L. (ed.) Sementes: qualidade fitossanitária. Viçosa: UFV, 2005. p.451-478.

8. Jaccoud Filho, D. S.; Manosso Neto, M. O.; Vrisman, C. M.; Henneberg, L.; Grabicoski, E. M. G.; Pierre, M. L. C.; Berger Neto, A.; Sartori, F. F.; Demarch, V. B. e Rocha, C. H. Análise, Distribuição e Quantificação do "Mofo Branco" em Diferentes Regiões Produtoras do Estado do Paraná. In: Reunião de Pesquisa de Soja da Região Central do Brasil, 31, 2010, Brasília. Resumos. Brasília, DF : EMBRAPA SOJA, 2010. p 226-228.

9. Juliatti, F. C.; Juliatti, F. C. Podridão branca da haste de soja: manejo e uso de fungicidas em busca da sustentabilidade nos sistemas de produção. Uberlândia: Gráfica Composer Editora, 2010. 35 p.

10. Leite, R. M. V. B. C. Ocorrência de doenças causadas por Sclerotinia sclerotiorum em girassol e soja. Comunicado Técnico, Londrina, n. 76 p.1-3. 2005.

11. Machado, J. C.; Oliveira, J. A.; Vieira, M. G. G. C.; Alves, M. C. Inoculação artificial de sementes de soja por fungos, utilizando manitol. Revista Brasileira de Sementes, Pelotas, v. 23, n. 2, p. 95-101, 2001.

12. Machado, A. Q. Uso da restrição hídrica em testes de sanidade de sementes de algodoeiro. 2002. 55 p. Dissertação (Mestrado em Fitopatologia) - Universidade Federal de Lavras, Lavras.

13. Machado, J. C.; Oliveira, J. A.; Vieira, G. M.; Alves, M. C. Uso da restrição hídrica na inoculação de fungos em sementes de algodoeiro (Gossypium hirsutum). Revista Brasileira de Sementes, Pelotas, v. 26, n. 1, p. 62-67, 2004.

14. Peres, A. P. Deteç̧ão de Sclerotinia sclerotiorum (Lib.) de Bary em sementes de feijoeiro (Phaseolus vulgaris L.) e soja (Glycine $\max ($ L.) Merril): desenvolvimento de metodologias. 1996. 51 p. Dissertação (Mestrado em Fitopatologia) - Universidade Federal de Lavras, Lavras.

15. Peres, A. P.; Machado, J. C.; Nasser, L. C. B. Metodologia para obtenção de sementes de feijão e soja infectadas com Sclerotinia sclerotiorum. Fitopatologia Brasileira, Brasília, v.23, n.3, p.413, 1998.

16. Peres, A. P.; Nasser, L. C.; Machado, J. C. Use of semi-seletive media for detection of Sclerotinia sclerotiorum on bean and soybean seeds. Fitopatologia Brasileira, Lavras, v. 27, n. 2, p. 123-126, 2002.

17. Rey, M. S.; Lima, N. B.; Santos, J.; Farias, C. R. J.; Pierobom, C. R. Crescimento micelial de raças de Colletotrichum lindemuthianum sob diferentes potenciais hídricos. Revista Brasileira Agrociência, Pelotas, v.11, n.3, p. 309-313, 2005.

18. Salisbury, F. B.; Ross, C. W. Plant physiology. 4.ed. Belmont: Wadsworth, 1991. 682p.

19. Santos, V. L. M. Avaliação da germinação e do vigor de sementes de genótipos de soja (Glycine max (L.) Merrill), submetidas a estresses salino e osmótico. 1994. 164p. Tese (Doutorado) - Universidade Federal de Viçosa, Viçosa.

20. Yang, X. B.; Workeneh, F.; Lundeen, P. First report of sclerotium production by Sclerotinia sclerotiorum in soil on infected soybean seeds. Plant Disease, St. Paul, v.82, p.264, 1998 